J. Biosoc. Sci., (2017) 49, 798-810 C Cambridge University Press, 2016. This is an Open Access article, distributed under the terms of the Creative Commons Attribution licence (http:// creativecommons.org/licenses/by/4.0/), which permits unrestricted re-use, distribution, and reproduction in any medium, provided the original work is properly cited.

doi:10.1017/S0021932016000602 First published online 8 Nov 2016

\title{
INFORMATION ABOUT METHODS RECEIVED BY CONTR ACEPTIVE USERS IN INDIA
}

\author{
ANRUDH K. JAIN ${ }^{1}$ \\ Population Council, New York, USA
}

\begin{abstract}
Summary. Very little is known, at national and state levels, about how much information women in India are receiving about the method of contraception they are using. The purpose of this study was to fill this gap in knowledge. A Method Information Index (MII) was calculated from the responses of women who started using a modern contraceptive method five years prior to interview, and who were still using it at the time of interview, in the third National Family Health Survey conducted in India in 2005-06. The women were asked whether at the time they initiated contraceptive use they were told about other methods they could use, the side-effects of their selected method and what to do if they experienced these side-effects. The MII values (percentages of women who responded 'yes' to all three questions) were calculated for each category of women's characteristics to show the relationship between MII and each characteristic. Mixed-effect logistic regression models were used to assess the independent effect of each variable after controlling for the effects of other variables on MII. The results indicate that contraceptive users in India in 2005-06 were receiving very little information about the method they were using: only $15.6 \%$ of contraceptive users reported receiving information on all three items. This low level was prevalent across different socioeconomic strata and across all the major states. There were a few exceptions, but the level was still quite low. Clearly, there is plenty of scope to improve the content of information exchanged between service providers and clients in order to ensure the rights of women to receive services of good quality, as well as improve informed choice and continuity of contraceptive use. Such a focus on improving quality of services is likely to help the Ministry of Health and Family Welfare in making its stated transition from a 'population control centric' to a 'reproductive rights based' approach to family planning in India.
\end{abstract}

\section{Introduction}

The 2012 London Summit on family planning reinvigorated global commitment to family planning and set a goal of providing modern contraceptive methods to

${ }^{1}$ Email: ajain@popcouncil.org 
120 million women with unmet need by 2020 in 69 of the poorest countries (' 120 by 20': a shorthand for this goal; Brown et al., 2014). The Ministry of Health and Family Welfare (MOHFW) of India has issued its own document entitled: 'India's Vision FP2020', in which the MOHFW has committed to reaching 48 million additional women with modern contraceptive methods by 2020 . Strategies to be followed to achieve this goal have also been outlined in the Vision FP2020 document, which includes a focus on ensuring quality of services (Government of India, 2014a).

Three components of quality specified in India's Vision FP2020 document are: services, supplies and information. Information exchange between service providers and clients is one of the six important elements of a quality-of-care framework (Bruce, 1990). It is welcome news that the Vision FP2020 document has incorporated quality among the strategies to be followed because without an increased focus on good quality of care in India's family planning programme, there is a real danger of a resurgence of targets and incentives to meet the new goal of reaching 48 million additional users. However, very little is known about the type of information women using contraception in India are receiving about the method they are using. The purpose of this paper was to fill this gap in knowledge.

The total fertility rate in India has declined by more than 3 births per woman from about 6 births in the 1960s to about 2.4 births in 2011. The Modern Contraceptive Prevalence Rate (MCPR; percentage of women using a modern method, i.e. pill, IUD, injectable, condom or sterilization) increased to about $48.5 \%$ by $2005-06$, as measured by the third National Family Health Survey (NFHS-3) (IIPS, 2007). The value of the MCPR varies by state in India, which in part reflects the differences in the implementation of the family planning programme and in part cultural and other differences in the health and education achievements of the people. However, the method-mix has remained quite skewed in favour of sterilization: about $37 \%$ of women were sterilized, about 3\% were using pills, about $2 \%$ were using an IUD and about $5 \%$ were using condoms in the NFHS-3 (IIPS, 2007). This skewed method-mix partly reflects the effect of the constrained methods choice available in the country, which over time may have also influenced women's stated preferences for permanent methods.

With such a high use of permanent methods with no discontinuation, the issue of quality in India may not be important for improving continuation, but it is still important because sterilized women have a right to receive services of good quality and a basic level of information about contraceptive methods in order to make an informed choice. Furthermore, the issue of quality remains important for those adopting reversible methods because better (perceived or actual) quality and information received at the time of contraceptive initiation is likely to improve subsequent continuation of contraceptive use (see e.g. Koening et al., 1997; RamaRao et al., 2003; Sanogo et al., 2003; Jain et al., 2012).

According to the NFHS-3, the one-year discontinuation rate in India in 2005-06 was high, at about $42 \%$ for modern reversible methods. The discontinuation rate for injectables was highest (53\%), followed by the pill (4\%), condom (45\%) and IUD (20\%). Only one in ten users switched to another method after discontinuation. This survey further documented that about $22 \%$ of women in India had an unmet need for contraception in 2005-06 (IIPS, 2007). Past users who continued to have an unmet need accounted for $27 \%$ of this current unmet need. Persistence of high contraceptive discontinuation in the future is likely to contribute another $10 \%$ of current users to unmet need (Jain et al., 2013). These two percentages, reflecting the potential 
contribution of contraceptive discontinuation to unmet need in India, are lower than those estimated for neighbouring countries (Bangladesh and Pakistan), primarily due to the higher use of sterilization (with no discontinuation) in India. They are still quite significant, however, in terms of absolute numbers of women who discontinue the use of contraception but continue to have unmet need. Moreover, this issue will become even more important as efforts are made to shift the method-mix towards reversible methods in the country, which is a laudable goal, as outlined in India's FP2020 Vision document mentioned above (Government of India, 2014a).

A reduction in contraceptive discontinuation among women using reversible methods, especially by encouraging them to switch to another reversible or permanent method appropriate to their needs and circumstances instead of stopping contraceptive use altogether, will help the MOHFW to achieve the overall goal set for 2020. Some of the ways this can be done include expanding the contraceptive choice available to women (Jain, 1989; Ross \& Hardee, 2013; Ross \& Stover, 2013) and to inform them about the method selected and the possibility of switching (RamaRao et al., 2003, Jain et al., 2012, Jain et al., 2013). However, data on the extent to which contraceptive users in India have been receiving this type of information are limited at the national and state level. For example, a facility survey conducted in 2003 focused on infrastructure and commodities, but did not collect any information from contraceptive users about the quality of care they received (Ram et al., 2005).

The purpose of this paper was to fill this gap in knowledge by documenting the level and correlates of the extent to which women received information about the contraceptive method they were using in 2005-06. This was done by analysing data from the NFHS-3 conducted in 2005-06. The results of this analysis can be used as a baseline against which progress can be measured for a critical element of quality as the results from NFHS-4 become available. There is very little information about how India and its states are doing in offering quality services, and for the first time this study presents results about how the country as a whole and its major states are doing in conveying critical information to contraceptive users about the method they are using.

\section{Methods}

The NFHS-3 was based on a nationally representative sample of 109,041 households and 124,385 women aged 15-49 years covering $99 \%$ of India's population living in 29 states. Of the 93,089 currently married women included in the survey, about $48.5 \%$ or 45,148 were using a modern method of contraception. The current study was based on 13,152 currently married women who were using the pill, IUD, injectable or sterilization at interview in the NFHS-3 and who started using it during the previous five years. These women were asked whether or not at that time (when they started using the method) they were told about the side-effects of the method they currently used, what to do if they experienced these sideeffects and about other methods they could use. In addition, women who were sterilized were also asked whether or not they were told that sterilization was permanent (IIPS, 2007). While these questions do not cover all aspects of information exchange between service providers and clients, they do capture some important components.

These data were used to create the Method Information Index (MII) which was included among the core indicators identified by the FP2020 - a global partnership to monitor 
progress towards achieving the goal of ' 120 by 20 '. The FP2020 included three questions to create this index (FP2020, 2015). In order to be comparable with the global results (FP2020, 2015; Jain, 2016), in this analysis the MII was also estimated from the responses to three questions. Given the high prevalence of sterilization in India, the analysis also included the percentage of sterilized women who reported being told that sterilization was permanent.

The MII values for pill, IUD and injectable users, and for those who were sterilized, were calculated from the percentage of users who responded 'yes' to all three questions listed below:

- Were you told about other methods?

- Were you told about side-effects of the method selected?

- Were you told what to do if you experience these side-effects?

The overall value of MII was estimated by the weighted average of method-specific MIIs, weights being the proportion of users using that specific method. The values of MII for each method, as well as for all methods combined, can range from 0 to 100 . The maximum value of 100 for MII indicates that all women reported 'yes' on all questions, i.e. they reported receiving information on all components, and the minimum value of 0 indicates that no woman reported receiving information on all components. The goal of the national family planning programme should be to reach the maximum score of 100 on MII and each of its components, i.e. ensuring that all women receive information on all components. A 'no information' index was also created to show the percentage of women who reported receiving no information on any component. While the two indexes are correlated, the 'no information' index indicates the extent to which women are not receiving any information about the method they are using.

In order to explore the correlates of MII, the following variables were included: type of method being used (coded as pill, IUD, injectable and sterilization), source of supply (coded as public or private), place of residence (rural or urban), household wealth (divided into five quintiles as per the NFHS), women's education (coded as none, primary, secondary or higher), women's age (coded in five-year age groups) and duration between contraceptive initiation within previous five years and interview (coded as $0-1,1-2,2-3,3-4,4-5$ years).

The values of MII were estimated for each category of these variables to show the relationship between MII and the variables. Sample weights were used to estimate the values of MII. Mixed-effect logistic regression models were then used to assess the independent effect of each variable after controlling for the effects of other variables on MII. A state variable with 29 categories was used in the fixed part of the model and a primary sampling unit (PSU) with 3459 categories was used as a random component. This was done to incorporate the effect of clustering of respondents within a PSU and within a state. The 'xt-logit' command for the multi-level regression analysis was used. All statistical analysis was carried out using Stata SE version 11.

\section{Results}

\section{Information indexes at the national level}

Figure 1 shows the percentage of current pill, IUD, injectable and sterilization users who reported receiving information about the side-effects of the method being used, how to manage these side-effects and about another method at the time they initiated using this 


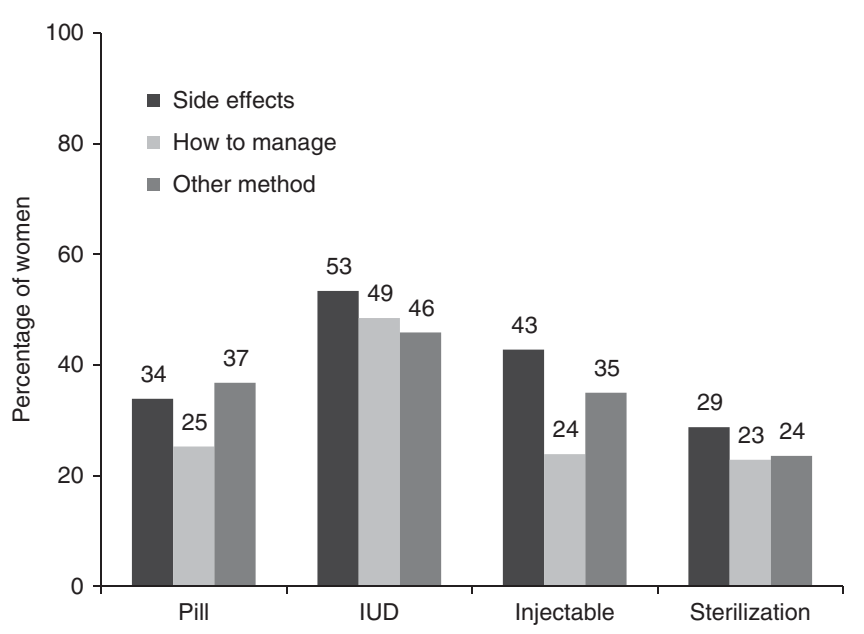

Fig. 1. Percentage of contraceptive users in 2005-06 who reported receiving information about their method at its initiation within the five years prior to interview in India, 2005-06.

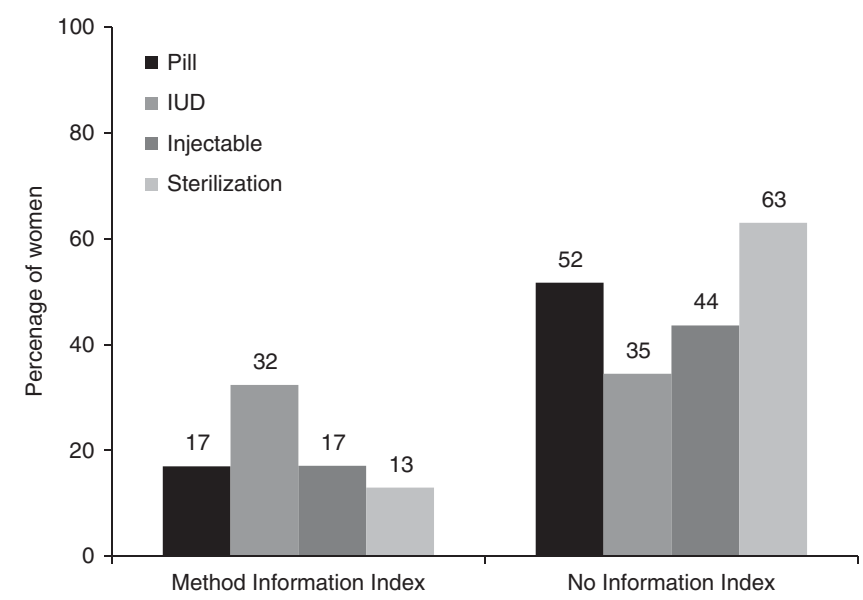

Fig. 2. Method Information Index and 'no information' index by method used in India, 2005-06.

method within the previous five years. About $50 \%$ of IUD users reported receiving information on each of these three items. While this level for IUD users is much higher than for the users of other methods, it is still less than the maximum possible score of 100 . Between 25 and $30 \%$ of sterilized women reported receiving information about these three items. Compared with other methods, the lowest percentage of sterilized women reported receiving information on each item. In addition, about one in three sterilized women reported that they were not told that the sterilization operation was permanent.

The values of the MII and 'no information' index for each method are shown in Fig. 2. The value of MII was highest for IUD users (32\%) and lowest for those who were sterilized $(13 \%)$. About one in three women using an IUD reported receiving 
information on all items in comparison to one in ten sterilized women. About one in two current users of the pill reported receiving 'no information' in comparison to two in three sterilized women.

Table 1 shows the estimated values and adjusted odds ratios of MII by women's characteristics. Except for current method use, all other results are presented for all methods (pill, IUD, injectable and sterilization) combined. The value of MII for all women and methods combined was very low at only $15.6 \%$, which means that a small number of women (one in six) reported receiving information on all items. The value of MII was uniformly low in all socioeconomic strata of society, except it was slightly higher for women using the IUD, living in urban areas, living in the richer households and those with at least secondary level education (see column 2, Table 1). In contrast, one in two women (about 58\%) received no information at all. This level was uniformly high in all strata of society. This means that the remaining $25 \%$ reported receiving information on some items but not all (data not shown).

In comparison to the pill users, the odds of receiving full information was much higher among the IUD users $(\mathrm{AOR}=1.59, p<0.001)$ and much lower for those who were sterilized $(\mathrm{AOR}=0.64, p<0.001)$. The likelihood of receiving full information by women who obtained their method from a private source was less than among those who obtained it from a public sector source $(\mathrm{AOR}=0.84, p<0.05)$. The likelihood of receiving full information for women living in rural areas was less than among those living in urban areas $(\mathrm{AOR}=0.73, p<0.01)$. The likelihood of receiving full information increased with women's education and reached significance level for those with secondary or higher level education (AOR $=1.39, p<0.001$ for secondary level, and AOR $=2.05, p<0.001$ for higher level). None of the AORs for household wealth categories reached statistical significance, i.e. household wealth did not seem to have any independent effect on MII.

\section{State-level variations}

Table 2 shows the state-level variations in the modern contraceptive prevalence rate (MCPR) and values of MII, along with the values for each of its components. The percentage of women who reported being told about side-effects and how to manage them and about another method are shown for all methods combined. The values of MII, based on these three items, are also shown for all methods combined. In addition, the percentage of women who were told that sterilization was permanent is shown separately only for those who were sterilized. While all 29 states were included in the analysis, the results are only shown for the fifteen major states.

Across all states, irrespective of the level of MCPR, the values of MII and its components were uniformly low, except in Tamil Nadu. About 32\% of women in India reported receiving information about side-effects associated with the method currently used. This level varied from about $11 \%$ in Bihar to a little over $40 \%$ in Kerala and Haryana and $63 \%$ in Tamil Nadu. About 26\% reported receiving information on how to manage these side-effects. This level varied between $9 \%$ in Bihar to between 33 and 35\% in four states and $58 \%$ in Tamil Nadu. About $28 \%$ of women in India reported receiving information about another method, implying some choice in method selection. This level varied between 14\% in Andhra Pradesh and Orissa to a little over 40\% in Madhya 
Table 1. Method Information Index (MII) and Adjusted Odds Ratios (AORs) by women's characteristics, India, 2005-06

\begin{tabular}{|c|c|c|c|}
\hline Characteristic & MII (\%) & $\mathrm{AOR}^{\mathrm{a}}$ & $n$ \\
\hline \multicolumn{4}{|l|}{ Current method } \\
\hline Pill & 17.0 & 1.00 & 2846 \\
\hline IUD & 32.4 & $1.59 * * *$ & 1602 \\
\hline Injectable & 17.1 & $1.68 *$ & 125 \\
\hline Sterilization & 13.1 & $0.64 * * *$ & 8578 \\
\hline \multicolumn{4}{|c|}{ Recent source of supply } \\
\hline Government & 14.2 & 1.00 & 8018 \\
\hline Private & 18.4 & $0.84 *$ & 4502 \\
\hline \multicolumn{4}{|l|}{ Place of residence } \\
\hline Urban & 21.4 & 1.00 & 5833 \\
\hline Rural & 12.8 & $0.73^{* *}$ & 7319 \\
\hline \multicolumn{4}{|c|}{ Household wealth quintile } \\
\hline Poorest & 11.5 & 1.00 & 1537 \\
\hline Poorer & 11.1 & 0.93 & 2010 \\
\hline Middle & 14.1 & 1.00 & 2709 \\
\hline Richer & 16.2 & 1.03 & 3322 \\
\hline Richest & 24.1 & 1.22 & 3574 \\
\hline \multicolumn{4}{|c|}{ Women's education } \\
\hline No education & 11.1 & 1.00 & 4412 \\
\hline Primary & 13.6 & 1.11 & 1994 \\
\hline Secondary & 18.6 & $1.39 * * *$ & 5619 \\
\hline Higher & 29.8 & $2.05^{* * *}$ & 1127 \\
\hline \multicolumn{4}{|c|}{ Women's age (years) } \\
\hline $15-19$ & 11.6 & 1.00 & 197 \\
\hline $20-24$ & 14.1 & 1.58 & 2657 \\
\hline $25-29$ & 15.6 & $1.74 *$ & 4807 \\
\hline $30-34$ & 17.0 & $1.94 *$ & 3496 \\
\hline $35-39$ & 15.4 & $1.99 *$ & 1479 \\
\hline $40-44$ & 16.5 & 1.80 & 426 \\
\hline $45-49$ & 19.8 & 1.78 & 90 \\
\hline \multicolumn{4}{|c|}{ Duration between contraceptive initiation and interview (years) } \\
\hline $0-1$ & 16.5 & 1.00 & 3737 \\
\hline $1-2$ & 16.6 & 1.01 & 2781 \\
\hline $2-3$ & 16.5 & 0.96 & 2539 \\
\hline $3-4$ & 14.0 & 0.89 & 2222 \\
\hline $4-5$ & 12.7 & 0.81 & 1873 \\
\hline Total $(\%)$ & 15.6 & & \\
\hline Constant & & $0.126^{* * *}$ & \\
\hline No. observations & 13,152 & 13,102 & 13,152 \\
\hline
\end{tabular}

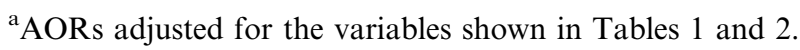

$* p<0.05 ; * * p<0.01 ; * * * p<0.001$. 
Table 2. Modern Contraceptive Prevalence Rate (MCPR) and Method Information Index (MII) for major states in India, 2005-06

\begin{tabular}{|c|c|c|c|c|c|c|c|}
\hline \multirow[b]{2}{*}{ State } & \multirow[b]{2}{*}{ MCPR } & \multicolumn{4}{|c|}{$\begin{array}{l}\text { Percentage current users reporting receiving } \\
\text { information }\end{array}$} & \multirow[b]{2}{*}{$\mathrm{MII}^{\mathrm{c}}$} & \multirow[b]{2}{*}{ AOR } \\
\hline & & $\begin{array}{l}\text { Side- } \\
\text { effects }^{\mathrm{a}}\end{array}$ & $\begin{array}{l}\text { How to manage } \\
\text { side-effects }\end{array}$ & $\begin{array}{l}\text { Another } \\
\text { method }^{\text {a }}\end{array}$ & $\begin{array}{l}\text { Sterilization } \\
\text { permanent }^{\mathrm{b}}\end{array}$ & & \\
\hline Orissa & 44.7 & 20.7 & 15.2 & 14.0 & 78.1 & 6.4 & $0.35^{* * *}$ \\
\hline Andhra Pradesh & 67.0 & 21.3 & 15.9 & 14.5 & 63.7 & 6.4 & $0.42^{* * *}$ \\
\hline Bihar & 28.9 & 11.1 & 8.9 & 28.2 & 61.7 & 6.7 & $0.51^{*}$ \\
\hline Uttar Pradesh & 29.3 & 28.4 & 20.7 & 20.0 & 56.0 & 9.3 & $0.53^{* *}$ \\
\hline Maharashtra & 64.9 & 30.0 & 25.4 & 20.7 & 65.9 & 11.0 & $0.53 * *$ \\
\hline Rajasthan & 44.4 & 29.9 & 23.7 & 25.1 & 56.8 & 13.3 & 0.90 \\
\hline West Bengal & 49.9 & 28.8 & 21.3 & 29.7 & 71.3 & 12.9 & 0.91 \\
\hline Karnataka & 62.5 & 28.4 & 23.2 & 25.6 & 64.5 & 15.7 & 1.00 \\
\hline Punjab & 56.1 & 37.5 & 30.0 & 32.3 & 64.0 & 18.9 & 1.15 \\
\hline Kerala & 57.9 & 44.5 & 33.3 & 33.3 & 66.0 & 21.6 & 1.44 \\
\hline Gujarat & 56.5 & 37.2 & 34.0 & 34.4 & 58.2 & 22.7 & 1.59 \\
\hline Haryana & 58.3 & 41.1 & 29.4 & 43.5 & 70.1 & 23.3 & $1.91 *$ \\
\hline Assam & 27.0 & 41.9 & 34.6 & 34.9 & 85.6 & 22.9 & $1.93 * *$ \\
\hline Madhya Pradesh & 52.8 & 45.0 & 34.9 & 41.6 & 68.4 & 25.7 & $2.49^{* * *}$ \\
\hline Tamil Nadu & 60.0 & 62.8 & 58.0 & 50.3 & 82.5 & 39.4 & $3.93 * * *$ \\
\hline India & 48.5 & 32.0 & 25.6 & 28.0 & 65.7 & 15.6 & na \\
\hline Weighted $N$ & 87925 & 13152 & 13152 & 13152 & 8578 & 13152 & 13102 \\
\hline
\end{tabular}

na, not applicable; AOR, adjusted OR for variables shown in Table 1.

${ }^{a}$ All methods combined.

${ }^{\mathrm{b}}$ Asked of sterilized women only.

${ }^{\mathrm{c}}$ All methods combined and three information elements combined.

Pradesh and Haryana and 50\% in Tamil Nadu. About $66 \%$ of sterilized women reported receiving information about the method being permanent. This level varied between $56 \%$ in Rajasthan and Uttar Pradesh to $83 \%$ in Tamil Nadu and $86 \%$ in Assam. This means that a substantial proportion of sterilized women - varying from 14\% in Assam to $44 \%$ in Rajasthan and Uttar Pradesh - reported that they were not even told that the method was permanent. The value of MII varied between about 6-7\% in Andhra Pradesh, Bihar and Orissa and 39\% in Tamil Nadu. The value of MII was less than, or close to, $25 \%$ in all states, except Tamil Nadu.

The values of the AORs indicate the net effect of state of residence after controlling for all other variables included in the model (listed in Table 1). A regional pattern among states (e.g. southern vs northern) similar to that observed for MCPR was not observed for MII. For example, the MCPR in Andhra Pradesh was $67 \%$ in comparison to $29 \%$ in Bihar. However, the value of MII in both states was about $6 \%$. For this reason, states in a particular region were not used as the reference category. Instead, Karnataka state, with a MII of 15.7, which is close to the value of 15.6 for India, was used as the reference category. These fifteen major states can be divided into four categories based on the value of AOR. The odds of receiving full information among women in Orissa state was 


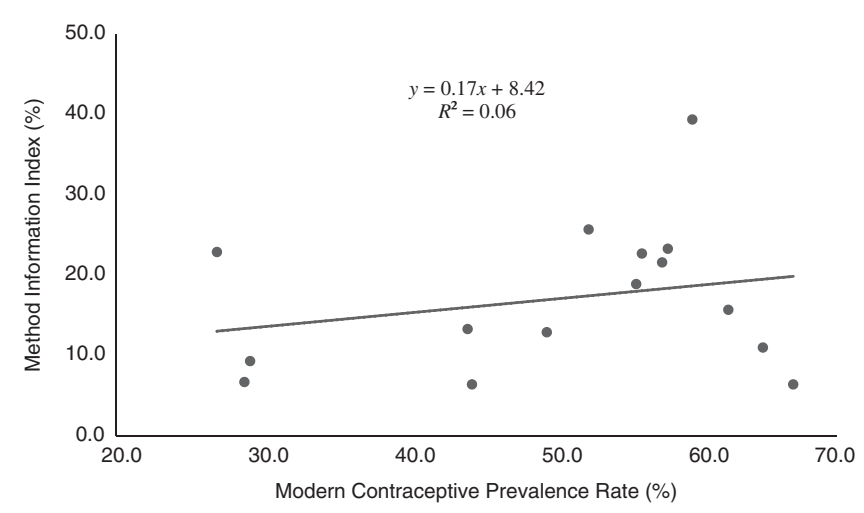

Fig. 3. Method Information Index and Modern Contraceptive Prevalence Rate (MCPR) for major states of India, 2005-06.

the lowest at about one-third of those living in Karnataka. The second category consisted of Andhra Pradesh, Bihar, Maharashtra and Uttar Pradesh. The odds of receiving full information among women living in these states was about one-half of that for those living in Karnataka. The third category consisted of Gujarat, Karnataka, Kerala, Punjab, Rajasthan and West Bengal. The values of AORs for these states were not significantly different from 1.00. The fourth category consisted of Assam, Haryana, Madhya Pradesh and Tamil Nadu. The odds of receiving full information among women living in these states was significantly higher than for those living in Karnataka.

Figure 3 shows that there was no association between the level of modern contraceptive prevalence achieved in a state and the value of MII. This lack of association between MCPR and MII suggests that across the country, irrespective of differences in the implementation of the family planning programme or differences in the socioeconomic conditions of its people, women were not receiving information on these three elements. This may also suggest that either the health providers did not have this type of crucial information about these modern methods or they didn't share this information with women, or that women didn't remember being told about this information. Furthermore, it also implies that there is ample room for improvement in all states.

This analysis was also repeated including the question about permanency of sterilization. The overall value of MII decreased from 15.6 to 14.5, and the MII value for sterilization decreased from 13.1 to 11.6. However, it did not affect any other relationship between MII and women's characteristics, state of residence or MCPR.

\section{Discussion}

The present analysis of three questions asked in the NFHS-3 survey about what women were told about the contraceptive method they currently used in 2005-06 shows that, in general, few women reported receiving information at the time of initiation (within the five years prior to interview) of the method they were currently using. For example, the value of MII for the country was only 15.6, i.e. $15.6 \%$ of women using a contraceptive method reported receiving information on all items. In contrast, about $58 \%$ of women 
did not receive information on any item and the remaining 26\% received incomplete information on some but not all of these three items.

Except women using an IUD, the value of this index was uniformly low in almost all strata of society. A higher percentage of women living in urban areas, or with higher education, also reported receiving information on these items than women living in rural areas or those with lower education. It is not clear whether the service providers treated them better and told them this information, they were better able to retain the information or they obtained it from other sources. With the exception of Tamil Nadu, this level was uniformly low in all states. Even in Tamil Nadu, the value of MII was low at $39 \%$. This level was much lower than the maximum score of 100 for the method information index. With such a low level of information given to woman, it is no wonder that discontinuation of reversible methods was high.

Admittedly, retrospective reports in a cross-sectional survey may suffer from memory and other biases. The reported answers to these questions will reflect what women may remember about what they were told at the time of contraceptive initiation and what they may have learnt about the method from other sources. Nevertheless, the extremely low levels of information reported being received by women in all strata and all states cannot simply be attributed to these factors.

Since sterilization has been a dominant contraceptive method for many decades in India, providers may be tempted to assume that information about its permanency will be well known to the overwhelming majority of women in the country. Thus they may not feel the need to inform women about the permanency of the operation. Such an assumption is not supported by this analysis. The results find that only two in three women reported being told that sterilization was permanent. This percentage may also include those women who may have learnt about it from other sources. The remaining one in three women reported that they were not told about the permanency of the method. These women may not have remembered being told about the permanency of sterilization and may not have learnt this from other sources.

The value of MII (15.6) in India in 2005-06 was low in comparison to that of other countries. For example, an analysis of changes in MII over five years in 25 developing countries indicates that MII varied between about 19 in Pakistan to 64 in Tanzania (Jain, 2016). One of the reasons for a lower value of MII in India may be the predominant use of sterilization, because fewer sterilized women reported receiving information. The results of the upcoming NFHS-4 will demonstrate the progress made in India over last 10 years in the value of MII. Preliminary data on the percentage of users who reported being told about side-effects in NFHS-4 indicate a limited improvement over the last 10 years (IIPS, 2016). Global data suggest an improvement of about 5 percentage points in MII over a period of five years (Jain, 2016). Even if the level of MII in India triples from 15.6 to $47 \%$, is ample room will remain for further improvement in providing information to women.

Monitoring the value of MII through cross-sectional surveys at national, state and district level in India is important to assess the progress being made in one critical element of quality. In doing so, however, it would be important to consider some other important issues about the coverage and validity of answers. For example, these three or four questions were asked of women who were using contraception at interview but not of those who discontinued the method during the reference period. Thus it cannot be 
ascertained whether provision of information on side-effects decreased or increased continuation of use. Furthermore, it is not known whether these questions adequately reflect the content of information exchanged between providers and clients, and whether valid answers to a larger number of questions can be obtained in a cross-sectional survey. Nevertheless, it may be important to ask another question from the users of reversible methods: whether or not they were told about the possibility of switching. This information will send a message to users that it is acceptable to switch to another method. Moreover, inclusion of this question will make it possible to include information on four questions from all users in creating an overall Method Information Index.

In the aftermath of deaths reported in a 'sterilization camp' in Chhattisgarh in 2014, the MOHFW issued revised guidelines for providing and improving sterilization services. These guidelines naturally focused mainly on reducing and eliminating deaths associated with the way sterilization services are provided in the country (Government of India, 2014b). While these guidelines are being operationalized, and service provision is shifting away from the 'camp' approach, it is extremely important to start focusing attention on other aspects of quality of care such as providing choice among a basket of contraceptive methods, improving information exchange between providers and clients, and ensuring follow-up and continuity of use for those who want to space or limit childbearing. The results of this study clearly demonstrate the paucity of information provided to women during the service-giving process.

Sometimes health service providers may not communicate with (or withhold information from) the patient receiving care for several reasons: status difference between medical professionals and patients, and, sometimes, due to pressures to meet the demand for services on any given day. But women coming for family planning services are not sick and should not be treated as such, and efforts need to be made to improve communication between providers and clients. For example, before making an incision for sterilization, the doctor can and must ask a few questions of the woman, especially whether she wants to stop childbearing completely, whether she knows that the operation is permanent and what to expect after the operation in terms of possible side-effects and how to manage them if they occur. A similar type of communication (including how to use the method, what to expect in terms of side-effects and how to manage them, when to come back for resupply and the possibility of switching when the method does not remain suitable) is also important for the provision of reversible methods, especially for improving use-effectiveness and continuity of their use.

The document on India's FP2020 Vision asserts: 'Transitioning from a population control centric approach to a reproductive rights based approach is the outcome of the experience gained in the last 50 years' (Government of India, 2014a, p. 29). This is a noble goal. A population centric approach focuses on numbers but a reproductive rights based approach implies a focus on individual well-being. Thus, the transition from a 'population centric approach' to 'a reproductive rights approach' is unlikely to become a reality without paying attention to the elements of quality of care, including informed choice among methods and the content of information exchanged between providers and clients. This is extremely important for all methods, but particularly important for sterilization, IUD and other clinical methods. In view of the asserted shift from a 'population centric approach' to a 'reproductive right based approach,' as mentioned in 
India's FP2020 Vision, perhaps the goal for 2020 in India should be changed from ' 48 by 2020 ' to '48 by 2020 with quality.'

\section{Acknowledgments}

This paper was prepared under the Measuring and Monitoring Quality of Services and Quality of Care project funded by a grant to the Population Council from the David and Lucile Packard Foundation. An earlier version of this paper was presented at a workshop on Quality of Health Care: Measurement \& Efforts to Improve Quality held in Neemrana Fort-Palace, India, June $30^{\text {th }}-$ July 1 st 2015 . The author gratefully acknowledges the Packard Foundation's support, and helpful suggestions received on an earlier version from Aparna Jain and John T. Townsend of the Population Council.

\section{References}

Brown, W., Druce, N., Bunting, J., Radloff, S., Koroma, D., Gupta, S. et al. (2014) Developing the " 120 by 20 " goal for the Global FP2020 Initiative. Studies in family Planning 45(1), $73-84$.

Bruce, J. (1990) Fundamental elements of the quality of care: a simple framework. Studies in Family Planning 21(2), 61-91.

FP2020 (2015) FP2020 Commitment to Action. Measurement Annex, November 2015. URL: http:// progress.familyplanning2020.org/uploads/03/00/FP2020_MeasurementAnnex_2015_ PrinterFriendly.pdf (accessed 8th March, 2016).

Government of India (2014a) India's Vision FP 2020. Ministry of Health and Family Welfare (MOHFW), New Delhi. URL: http://ec2-54-210-230-186.compute-1.amazonaws.com/ wp-content/uploads/2015/04/Indias-Vision-FP2020.pdf (accessed 17th August 2015).

Government of India (2014b) Standards \& Quality Assurance in Sterilization Services. Ministry of Health and Family Welfare (MOHFW), New Delhi. URL: http://nrhm.gov.in/images/pdf/ programmes/family-planing/guidelines/Standards_and_Quality_Assurance.pdf (accessed 24th August, 2015).

International Institute for Population Studies (IIPS) \& Macro International (2007) National Family Health Survey (NFHS-3), 2005-06: India: Volume I. IIPS, Mumbai.

International Institute for Population Studies (IIPS) (2016) National Family Health Survey (NFHS-4), 2015-16 State-level Fact Sheets. URL: http://rchiips.org/NFHS/factsheet_NFHS-4. shtml (accessed 8th March 2016).

Jain, A. K. (1989) Fertility reduction and quality of family planning services. Studies in Family Planning 20(1), 1-16.

Jain, A. K. (2016) Examining progress and equity in information received by women using a modern method in 25 developing countries. International Perspectives on Sexual and Reproductive Health 42(3).

Jain, A. K., Obare, F., RamaRao, S. \& Askew, I. (2013) Reducing unmet need by supporting women with met need. International Perspectives on Sexual and Reproductive Health 39(3), 133-141.

Jain, A. K., RamaRao, S., Kim, J. \& Costello, M. (2012) Evaluation of an intervention to improve quality of care in family planning programme in the Philippines. Journal of Biosocial Science 44(1), 27-41.

Koenig, M. A., Hossain, M. B. \& Whittaker, M. (1997) The influence of quality of care upon contraceptive use in rural Bangladesh. Studies in Family Planning 28(4), 278-289. 
Ram, F., Paswan, B. \& Ladu Singh, L. (2005) India Facility Survey. International Institute for Population Studies, Mumbai.

RamaRao, S., Lacuesta, M., Costello, M., Pangolibay, B. \& Jones, H. (2003) The link between quality of care and contraceptive use. International Family Planning Perspectives 29(2), 76-83.

Ross, J. \& Hardee, K. (2013) Access to contraceptive methods and prevalence of use. Journal of Biosocial Science 45(6), 761-778.

Ross, J. \& Stover, J. (2013) Use of modern contraception increases when more methods become available: analysis of evidence from 1982-2009. Global Health: Science and Practice 1(2), 203-212.

Sanogo, D., RamaRao, S., Jones, H., N'diaye, P., M'bow, B. \& Diop, C. B. (2003) Improving quality of care and use of contraceptives in Senegal. African Journal of Reproductive Health 7(2), 57-73. 